applying such measures were promptly and admirably carried out. With respect to the origin and causes of the outbreak on the Nubia a good deal of doubt has been expressed, and the view that the source of the cholera was first contracted at Port Said seems to be regarded as the most probable explanation. But is this so ? Do not the facts, on the other hand, point to Colombo? In the first place, it is strenuously denied that there was at the time, or had been recently, any cholera at Port Said or in Egypt. If this be so, it is not easy to understand how a disease or anything else can be communicated which neither the place nor the people had to communicate! Moreover, was the fruit consumed exclusively by the troops on board the Nubia or by those first attacked? But the period of incubation, it is alleged, fits in with the assumption that the source of the cholera was Egypt and not Colombo. We will touch upon this point subsequently. That cholera existed at Colombo at the time the Nubia was at that port may be taken as a fact; that she there embarked a number of troops of the North Lancashire Regiment-and possibly other soldiers-is also a fact; and, still more interesting, the disease seems to have originated among the men of the North Lancashire Regiment and to have been confined to the military on board; in other words, on the assumption that they carried cholera on board with them they seem to have kept it. The date of the first fatal case actually ascribed to cholera is given as Jan. 2nd-a long interval; but it does not at all follow that some of the baggage, stores, or clothing shipped with the troops at Colombo may not have been opened and exposed subsequently to the departure of the Nubia from that port. Be this as it may, however-and we only put it forward hypothetically - the occurrence of cholera in vessels leaving cholera-infected ports at dates beyond the recognised and usually short period of incubation of this disease is not by any means an unknown phenomenon. On the contrary, it would not be at all difficult to adduce instances of the kind from the published records of outbreaks of cholera on ships-of the occurrence, for example, of the first fatai case of cholera from the seventh to the sixteenth day of the voyage and even after the twentieth day. To take the well-known case of the Renown. Cholera appeared in Gibraltar on Aug. 19th, 1865. On the 21st the headquarter wing of the 19th Regiment went on board that ship. On the 22 nd - the third day after the first fatal case of cholera in Gibraltara fatal case occurred on the ship. The vessel was hauled out into the bay and retained there for thirty hours ; and, no subsequent case having occurred, she proceeded on her voyage to the Cape. On Sept. 5th following, a fortnight after the fatal case at Gibraltar, there was an outbreak of cholera on board the Renoron which lasted fourteen days, and the period of this outbreak is stated to have corresponded to that of the maximum intensity of the epidemic in Gibraltar. The left wing of the same regiment, which departed from Gibraltar in another vessel on the very day cholera broke out at Gibraltar, altogether escaped the disease. In the case of the ship Gertrude again the facts are interesting. On May 21st, 1859, when a severe epidemic of cholera was prevailing at Calcutta, a number of sick and wounded men were embarked for passage to England. On June 15th following-twentyfour days after all communication with land had ceasedthe first fatal case occurred, and the outbreak lasted until June 25th--ten days. In the literature that exists on this subject it has been occasionally observed that the crews, troops, and others, if drawn from separate sources and shipped immediately before sailing, showed no community of attack, cholera being confined to those shipped from a definite quarter.

T'o return to the Nubia. It appears that the origin of the ousbreak cannot in this particular case be ascribed to the contamination of the water-supply; that vehicle of the disease was thoroughly investigated and eliminated as a cause because it was found to be inconsistent with the facts of the outbreak. No one can have any doubt, least of all readers of THE LANCET, of the great importance that is attached to the view that cholera is a water-borne disease, but that is very different from saying that it is exclusively so or that the poison must invariably be swallowed, with its consequent corollary and obvious moral that the only safeguard is-the kettle!

We do not pretend, of course, to say that the origin of the outbreak on board the Nubia is demonstrably attributable to the cause having been embarked at Colombo, but we do say that all the facts require to be ascertained and most carefully weighed before the correctness of that view be discarded, for. so far as we know them at present, and so far as the medical history of the outbreak goes, there seems to be a good deal to be said in favour of it. Where an opinion has to be based on the facts or on assumptions we prefer to range ourselves for the time being on the side of the facts so far as we know them.

\section{CONGRATULATIONS TO LORD LISTER.}

We have received the following letters for publication from the Registrar of the Royal College of Surgeons in Ireland :-

Royal College of Surgeons in Ireland, Jan. 9th, 1897. MY LORD, - The Council of the Royal College of Surgeons in Ireland have requested me to tender to you on their behalf and my own our earnest congratulations on your elevation to the peerage. We are glad to recognise that on the first occasion on which such an honour has been conferred upon a member of our profession the recipient should been conferred upon a member of our profession the recipient should saved innumerable lives. There is no place in which your precepts and saved innumerable lives. There is no place in which your precepts and practice have been more zealously followed than in this country, and the honour which has been conferred upon you by Her Majesty, and we trust that you may live long to exercise that influence upon tive we trust that you may live long to exercise that influence upo
practice of scientific surgery which has made your name famous. I am, My Lord, yours faithfully,
W. THomson, President.

[REPLY.]

12, Park-crescent, Portland-place, Jan. 12tin, 1897.

My dear Mr. Thomson,-I esteem it a very high honour to receive congratulation from the body which represents my Irish colleagues in surgery, and I feel it to be enhanced by the circumstance that the gratifying message has been communicated to me by yourself, the Pratifying message has

I well remember the kind part you took in reporting a small address I well remember the kind part you took in reporting a small address
that I gave many years ago in the Richmond Hospital, an act on your part which, I suspect, had no small share in diffusing among your Irisb rethren the principles of antiseptic surgery. I beg you to express to your colleagues on the Council the great gratufication which they hav $\rightarrow$ caused to me, and

Believe me, very sincerely yours, JOSEPH LISTER.

\section{THE LONDON WATER QUESTION.}

$A^{T}$ the meeting of the Society of Chemical Industry on Monday last an important paper on "The Character of the London Water Supply" was read by Mr. W. T. Dibdin, the chemist to the London County Council. The speaker first called attention to a point that has been largely overlooked-. viz., the character of the matters held in suspension in presumably pure waters. Although small in quantity these materials were often of such a kind as to throw considerable light on the source and quality of the water in a way that the old methods of analysis failed to do. For a considerable period daily analyses had been made of the water supplied to London by the different companies and of the water of the river Thames at the intakes of the companies deriving their supply from that source. After several improvements in the method of examination a specially constructed micro filter was at length employed, enabling the quantity of suspended matter to be suated volumetrically as millimetres per litre. A further advantage of this method was that the deposit could be used afterwards for microscopical examination. The quantities of suspended matters present in the Kent, West Middlesex, and New River waters during 1895 were practically the same-0 0011 grain per gallon-and Mr. Dibdin accepted this proportion as the unavoidable minimum due to "rust and dust." The average quantities present in the other London supplies, however, amounted to 0.0033 grain per gallon, leaving 0.0022 grain of aroidable suspended matter. If the West Middlesex was capable of so purifying Thames water as to reduce it to the high standard of the Kent and New River waters there was no reason why the other companies drawing their supplies from the Thames should not do the same. The average quantities of suspended matter in the various waters 